\title{
Açık Devlet Verisi Süreçlerine Dair Bir Model Önerisi
}

\author{
Ahmet Ercan Topcu ${ }^{1,2 *}$, Abdullah Işık ${ }^{3}$ \\ ${ }^{1}$ College of Engineering and Technology, American University of the Middle East, Kuwait (ORCID: 0000-0003-1929-5358) \\ ${ }_{2}^{2}$ Ankara Yıldırım Beyazıt Üniversitesi, Mühendislik Fakültesi, Bilgisayar Mühendisliği Bölümü, Ankara, Türkiye (ORCID: 0000-0003-1929-5358) \\ ${ }^{3}$ Ankara Yıldırım Beyazıt Üniversitesi, Mühendislik Fakültesi, Bilgisayar Mühendisliği Bölümü, Ankara, Türkiye (ORCID: 0000-0002-8344-025X)
}

(İlk Geliş Tarihi 3 Eylül 2019 ve Kabul Tarihi 4 Aralık 2019)

(DOI: 10.31590/ejosat.614933)

ATIF/REFERENCE: Topcu, A. E. \& Işık, A. (2019). Açık Devlet Verisi Süreçlerine Dair Bir Model Önerisi. Avrupa Bilim ve Teknoloji Dergisi, (17), 833-843.

\begin{abstract}
$\ddot{O} \mathbf{z}$
Kamu kurumları sundukları hizmetler sonucunda oldukça büyük miktarda veri barındırmaktadır ve barındırmayı da sürdürecektir. Birçok veri seti hassas içerik barındırmamasına rağmen genellikle erişime açık olmamakta ve bu veri setlerinden fayda sağlanamamaktadır. Her ne kadar farklı formatta ve başlıkta veri setleri söz konusu olsa da, bilgi teknolojilerindeki gelişmeler bu veri setlerinin diğer verilerle bağlanmasını ve paylaşımını oldukça kolay bir hale getirmektedir. Dünyada ekonominin veri odaklı olmasının da etkisiyle son yıllarda birçok ülke ellerindeki veriden en üst seviyede yararlanabilmek için veri ve bilgileri bilgisayarca okunabilir formatta belirli bir kullanım koşuluyla paylaşarak açık devlet verisi süreçlerini uygulamaya sokmuştur. Kamu verisinin açılması aynı zamanda hesap verilebilirliği artıracak, daha kaliteli ve yeni hizmetlere olanak sağlayacak, operasyon maliyetini düşürecek, kamu ve özel sektörde açık inovasyonu teşvik edecektir. Bu çalışmada amaç; birçok kaynakta farklı tanımlarla ifade edilen açık devlet verisine yönelik kapsayıcı bir tanım ortaya koymak, açık devlet verisini yapısal özellik, gelişim ve ihtiyaç sebebi, riskler ve potansiyel engeller, ekonomik boyut, standartlar, açık lisans, ölçümleme, araçlar başılılarını içeren bir çerçeve üzerinde ele almak ve kamu verisini açmaya yönelik bir model ortaya koymaktır.
\end{abstract}

Anahtar Kelimeler: Açık Devlet Verisi, Açık Devlet, Bilgi Ekonomisi, Katılımcılık, Şeffaflık, Hesap Verebilirlik.

\section{A New Model Proposal for Open Government Data Practices}

\begin{abstract}
Government institutions hold vast amounts of data, mostly produced through public services, and that has grown. Although these data sets have no sensitive content, usually they are not accessible and can not be benefitted. Even though data sets exist in different types and formats, developments at information technologies make it easy linking and sharing these data sets with other data. The data-driven economy is the new global approach and many countries gave start to some new open data policy approaches aim to make government data and information machine-readable. It became a new default to gain the maximum benefit from the data they have. Opening government data will also help to increase accountability, public service quality to decrease operational cost and to encourage open innovation at public and private organizations. This article aims to assert an illustration for open government data which has different definitions at many sources, to examine open government data within the scope of structure, value, potential risks, economic field, standards, open license, measurement, tools and to offer a model for the open government ecosystem.
\end{abstract}

Keywords: Open Government Data, Open Government, Data-Driven Economy, Participation, Transparency, Accountability.

\footnotetext{
* Sorumlu Yazar: College of Engineering and Technology, American University of the Middle East, Kuwait, ORCID: 0000-0003-1929-5358, ahmet.topcu@aum.edu.kw
} 


\section{Giriş}

Başta internet olmak üzere bilgi ve iletişim teknolojilerindeki gelişmeler insanların ve kurumların içeriği üretme, tüketme ve etkileşim yöntemini tamamen değiştirmiştir. Bu değişim kamu hizmetlerinin de dönüşümüne ivme kazandırarak birçok ülkenin edevlete yönelik dönüşümleri dijital politikalarının merkezinde olmasını sağlamıştır. Elektronik ortamda sağlanan hizmetlerin her geçen gün artması ülkedeki yönetişim mekanizmasına da olumlu bir şekilde yansımaktadır. Ayrıca tüm bu gelişmeler açık devlet verisine yönelik eylem planları, kamu verisinin açılması, vb. girişimlerde de bir artış sağlamıştır. Birçok ülkede açık devlet girişimine yönelik eylem planı ya da uygulama seviyesinde girişim söz konusudur.

Kamu kurumları sundukları hizmetler sonucunda oldukça büyük miktarda veri barındırmakta, ancak birçok veri seti hassas içerik barındırmamasına rağmen erişime açık olmamakta ve bu veri setlerinden fayda sağlanamamaktadır. Bilgi teknolojilerindeki gelişmeler bu veri setlerinin paylaşımını, diğer verilerle bağlanmasını oldukça kolay bir hale getirmektedir. Bahsedilen hususlardan ötürü, birçok devlet kamu sektörü verisini açarak internet üzerinden direkt olarak vatandaşlarının erişimine açmıştır. Şeffaflığa direkt olarak etki eden bu uygulamalar aynı zamanda farklı alanlarda birçok firsat sağlamaktadır. Ancak her ne kadar bu tarz bir girişimin yaygınlaşmasını engelleyen hususlar söz konusu olsa da devletler bu hususlara yönelik önlemler almaktadır. Tüm bunların neticesinde sivil toplum kurumları (STK), girişimciler, sivil uzmanlar ve diğer tüm kullanıcılar açık devlet verisini kullanarak topluma fayda sağlayabilecek yeni uygulamalar oluşturmaktadır.

\section{Materyal ve Metot}

$\mathrm{Bu}$ çalışma kapsamında; birçok akademik çalışma, kurum ve kuruluşlara ait raporlar, ülke örnekleri(eylem planları, hukuki düzenlemeler, vb.) gözden geçirilmiş, sivil toplum platformlarının faaliyetleri takip edilmiş, çeşitli endeksler ele alınmıştır. Sentezlenen bilgiler ışı̆̆ında da açık devlet verisi yapısal özellik, gelişim ve ihtiyaç sebebi, riskler ve potansiyel engeller, ekonomik boyut, standartlar, açık lisans, ölçümleme, araçlar başlıkları altında incelenmiştir. Ayrıca uluslarlarası sivil toplum kuruluşlarının faaliyetleri ve ülkelerin açık devlet verisine yönelik politika ve uygulamaları referans alınarak çalışma dâhilinde edinilen bulgular sonucunda oluşturulan model ifade edilmiştir.

\subsection{Açık Devlet Verisi}

Açık devlet verisi tekrar kullanılması amacıyla toplanan, saklanan ve dağıtımı yapılan kamu sektörü verileridir veya Parycek, Höchtl, Ginner'in belirttiği gibi kamu sektörü verilerinin kullanımı ve dağıtımında hiçbir kısıt olmadan devlet eliyle erişime açılmasıdır [1].

Açık devlet verisi kavramı kamu verilerinin erişime ve tekrar kullanıma açılması olarak tarif edilebilir. Paylaşılması halinde gizliliği, güvenliği, özel hayatı tehlikeye sokabilecek veriler ile kanunen paylaşılmayacağı belirtilmiş veriler açık devlet verisi kapsamına dâhil değildir. Kamu sektörü verileri belirli bir amaç için toplandıklarından ve belirlenen kullanım amacından daha fazlasını sunma potansiyelinden ötürü açık verinin önemli bir alt kümesidir [2].

Ubaldi paylaşılması halinde ekonomik ve sosyal değer yaratabilecek veri türlerini ifade etmiştir [3]. Belirtilmiş açık devlet verisi çeşitleri: ticari bilgiler (ticaret odalarına ait bilgiler, vb.), evrak, patent ve marka, kamu ihaleleri bilgileri, coğrafik bilgiler (adres bilgileri, uydu görüntüleri, tapu ve kadastro bilgileri, ulaşım ağları, topoğrafik bilgiler), hukuki bilgiler (yerel ve ulusal mahkeme kararları, kanunlar, anlaşmalar), meteorolojik bilgiler (iklim bilgileri ve modelleri, hava tahminleri), sosyal veriler (ekonomik, işsizlik, sağlık, toplumsal ve kamu yönetimi verileri) ulaşım bilgileri (trafik yoğunluk, yol çalışma, toplu taşıma, araç kayıt, vb. veriler) şeklindedir.

Deloitte raporuna göre başarılı bir açık devlet ekosisteminde 3 anahtar paydaş söz konusudur: devlet, özel sektör ve vatandaş [4]. Her bir aktör bir diğerine farklı türde veriler sunar. Devlet bu ekosisteme "üretilen, toplanan veya vatandaşın vergisiyle satın alınan ve hassas olmayan" veriyle katkıda bulunurken, özel sektör de kurumiçi üretilen verilerini belli kısıtlamalar ile paylaşır. Vatandaş işe kişisel ya da kişisel olmayan verileriyle bu ekosistemde yer alır. Kamu sektörü verisinin açılmasının amacı dijital dünyaya adapte olabilmek ve ulusal açık veri ekosistemine katkıda bulunmaktır [5].

\subsubsection{Yapısal Özellik}

Kamuda açık veri sürecine yönelik organizasyonların oluşturulması ve bu organizasyonların sürdürülebilirliği için açık verinin tanımının net bir şekilde yapılması ve bu tanım doğrultusunda ilgili esasların belirlenmesi oldukça önemlidir. Açık devlet verisi kavramına katkıda bulunmayı amaçlayan birçok araştırmacı ve organizasyon bu kavramın tanımına ve özelliklerine yönelik çalışmalarda bulunmuştur. Bu çalışmalardan en önemlilerinden biri Aralık 2007'de, Sebastopol'de 30 açık devlet araştırmacısının katıldığı, Public.Resource.Org tarafından organize edilen ve Sunlight Foundation, Google, Yahoo'nun da desteklediği Açık Devlet Çalışma Grubu Toplantısı'dır. Bu çalışmada açık devlet verisinin 8 karakteri ve ilgili diğer tanımlar belirlenmiştir [6]. Sebastopol listesinde yer alan ve tanımları üzerinde uzlaşılan tanımlara göre veri bütündür, ilkeldir, sürelidir, erişilebilirdir, makinece işlenebilirdir, sınırlanmamıştır, patentsizdir ve açık lisanslıdır.

ABD'de faaliyet gösteren bir sivil toplum kuruluşu olan Sunlight Foundation 2007 yılında Sebastopol, Kaliforniya'daki konferansta da yer almış ve Sebastopol listesini güncelleyerek 2010 yılında "Devlet Verisini Açmanın 10 Esası" başlığıyla bir bildiri yayınlamıştır. Bu esaslar: bütünlük, ilkellik, sürelilik, fiziksel ve elektronik ortamda kolayca erişilebilirlik, makinece okunabilirlik, fark gözetmeme, ortak veya açık standartların kullanımı, lisanslama, kalıcılık, kullanım maliyeti [7] şeklindedir. 


\section{Bütünlük}

Kamu kurumu tarafından paylaşılan veri setleri mümkün olduğunca tam olmalı ve toplanma maksadını iyi yansıtmalıdır. Kişisel verilerin gizliliğine yönelik regülasyonları ihlal etmeyecek tüm veriler ham halde paylaşılmalıdır. Ham veriyi tanımlayan meta veriye, anlamlı verilerin nasıl elde edildiğine dair formül ve açıklamalara da yer verilmelidir. Bahsedilen unsurların yerine getirilmesi kullanıcıların veriden en iyi şekilde yararlanmasına olanak sağlayacaktır.

\section{2.İlkellik}

İlkel formdaki veri en modüler halde tutulan ve birleştirilmeyip herhangi bir değişiklik yapılmayan veridir. Kamu kurumları tarafından paylaşılan veri kaynaktan alındığı gibi ham halde olmalıdır. Ayrıca kullanıcıların verilerin doğru ve nizami toplandığından emin olması adına veri toplama yöntemi de belirtilmelidir. Verinin modüler ve ham halde olması ve çoklu formatta paylaşılması aynı zamanda G8 Open Data Charter dokümanında "herkesin tarafından erişilebilirlik" kısmında da yer almıştır [8].

\section{Sürelilik}

Kamu kurumları tarafindan paylaşılacak veri kullanıcılara zamanında sunulmalıdır. En uygunu kamu kurumlarının veriyi topladıktan sonra hemen paylaşmasıdır. Elde edilecek faydanın zamanla ilişkisi yüksek olan verilere öncelik verilmelidir. Gerçek zamanlı güncellemeler de veriden elde edilecek faydayı artıracaktır. Verinin değerini kaybetmemesi için bir an önce sunulması gereklidir. Kamu için yararlı olacağı zaman diliminde değil de daha sonrasında verinin yayınlanmaması açık veri standartlarıyla uyuşmamaktadır. Birleşik Krallık Açık Veri Bildirisi'nde de "Kamu verisi güncel ve modülerdir [8]. Hükümetin açık veriye yaklaşımı bir araya getirilen verilerin ilgili vakadan çok sonra yayınlanması ile kısıtlı değildir." ve "Veriler bir an önce paylaşılır ve ardından bağlı veri formları da dahil olmak üzere açık standart formatına uyduğundan emin olunur." ifadeleri yer almaktadır. Ayrıca verilen güncel olması ile ilgili ifadeler G8 Open Data Charter dokümanında da yer almaktadır.

\section{Fiziksel Ve Elektronik Ortamda Kolayca Erişilebilirlik}

Kamu kurumları tarafından paylaşılan veri setlerine fiziksel ve elektronik ortamlardan erişim sağlanabilmelidir. Fiziksel erişimin sağlanması için kamu kurumlarında veri erişim talebini alacak ofisler ve veri paylaşım sürecini başlatacak talep formlarının oluşturulması gerekir. Verinin elektronik ortamdan erişimi de dokümanları tek seferde indirebilir ya da oluşturulacak uygulama programlama ara yüzü (API) ile anlık olarak sağlanabilir.

\section{Makinece Okunabilirlik}

Bilgisayarlar belli formattaki girdileri daha iyi yorumlayabilirler. Örnek olarak; el yazısıyla yazılmış karakterlerin yer aldığı bir dokümanın makinece işlenmesi oldukça zordur. Optik karakter tanıma (OCR) uygulamalarıyla taranan dokümanlarda birçok karakter hatasına rastlanmaktadır. Aynı şekilde PDF formatındaki dokümanların da makinece işlenmesi oldukça zordur. Tauberer (2014)'e göre veriyi paylaşan kurum okuyucunun içeriğe en rahat şekilde ulaşması (örn. PDF, Açık doküman formatı (ODF)), araştırmacının da içeriği analiz etmesi (örn. txt, csv) için çoklu formatta veri paylaşımı yapmalıdır [8]. ACM'nin açık devlet konulu raporunda bu esasa yönelik görüşünü "kamu kurumları tarafından paylaşılan veri setleri verilerin analiz edilmesine ve yeniden kullanımına uygun format ve yaklaşımlarla paylaşılmalıdır." şeklinde ifade etmiş̧tir [9].

\section{Fark gözetmeme}

Herhangi bir kişi herhangi bir veriye kendini sisteme tanıtmadan veya doğrulama gerçekleştirmeden erişebilmesidir. Open Knowledge Foundation'ın opendefinition.org'taki "Açık Bilgi Tanımı" başlı̆̆ında belirtilen "veriye erişebilirlik", Sunlight Foundation'ın "Açık Veri Politika Esasları" belgesinde "kamu verisinin çevrimiçi ortamda uygun şekilde paylaşımı" ve G8 Open Data Charter dokümanında "herkesin tarafından erişilebilirlik" kısımlarında verinin ücretsiz bir şekilde her kesime sunulması yer alır.

\section{Ortak veya Açık Standartların Kullanımı}

Bazı veri setlerinin paylaşılmasında tercih edilen bazı formatlar sadece ücretli yazılımlar tarafından açılmaktadır. Bu veri setlerinin paylaşımında açık kaynaklı ücretsiz yazııımların tercih edilmesi potansiyel kullanıcı sayısını da artıracaktır [7].

\section{Lisanslama}

Hizmet Kullanım Şartları gibi kıstlamalar verinin herkes tarafından kullanımına engel olan uygulamalardır [7]. Lisanlamanın sınırlamaları ortadan kaldıracak şekilde hazırlanması önem arz etmektedir.

\section{Kalıc1lik}

Kamu kurumlarının internet ortamında paylaştığı veriler arşivde tutulmalı ve kalıcı olmalıdır [7].

\section{Kullanım Maliyeti}

Tauberer'e göre veri internet üzerinde ücretsiz bir şekilde sunulmadığı sürece açık sayılmaz [8]. 2013 yılında güncellenen Avrupa Birliği Kamu Sektörü Bilgisi Direktifi (EU PSI Directive 2013/37/EU) doğrultusunda AB devletlerinin kuruluşları verilerin yeniden düzenlenmesi, toplanması, yayınlanması sürecinde oluşan marjinal maliyetten fazlasını talep edemeyeceği yer alarak 2003 yılında yayınlanan direktif (EU PSI Directive 2003/98/EC) ile bu kuruluşlara verilen "uygun bir kâr sağlayabilme" imtiyazı geri alınmıştır. İlgili direktifte her ne kadar ücret ifadesi geçse de Tauberer'e göre hali hazırdaki birçok kamu verisi söz konusu ve bu verilerin çevrimiçi olarak paylaşımının marjinal maliyeti neredeyse hiç yoktur [8]. 


\subsubsection{Gelişim ve İhtiyaç Sebebi}

Yu ve Robinson açık devlet verisine dair amaç ve gereklilikleri iki ana başlık altında toplamıştır. Bunlardan ilki demokratik değerlere hitap etmesidir [10]. Buna göre kamu verilerinin herkesin erişimine açılması aynı zamanda açık devlet süreçlerinin tanımlanmasına veya devlet yönetiminde şeffaflığa ve hesap verilebilirliğin artırılmasına aracı olmalıdır. İkinci başlık ise ekonomik sebeplerdir. Bu anlayışa göre kamu sahipliğ̆inde üretilmiş veriler özel sektör için bir avantaj sağlayabilir. Kamudaki bu kaynağın ücretsiz bir şekilde sunulması inovasyonu ve girişimciliği teșvik edecektir [11]. Özel sektörde oluşan bu yenilik kamuya ekonomik büyüme ve istihdam olarak geri dönecektir [12].

Safarov, Meijer ve Grimmelikhuijsen ise açık devlet verisinin bir ya da daha fazla etkisinin yer aldığı 82 çalışmayı incelemiştir. Bu çalışmalar sosyal ve ekonomik değerler ile iyi yönetişimin ekseninde ayrılmıştır ve ilgili çalışmalar üzerine yapılan tematik analiz sonucu altı önce çıkan etki başlığı belirlenmiştir [13]. Bunlar: şeffaflık ve hesap verebilirlik, ekonomik gelişim, vatandaşın katılımı, kamu hizmetlerinin gelişimi, sosyal değer ve vatandaşın güvenidir. İlgili çalışmadaki en önemli noktalardan biri analizin açık devlet verisinin etkisinin çıkarımsal ve gerçekleşenler ayrımı dâhilinde yapılmasıdır.

\subsubsection{Riskler ve Potansiyel Engeller}

Cowan, Alencar, Mcgarry bazı açık devlet uygulamalarını inceleyerek bu uygulamalar sırasında ortaya çıkan sorunları bir arada toplamıştır ve "kamu tarafından paylaşılan verilerin açık veri standartlarına uyması, açık devlet verisine erişim, açık devlet verisinin doğru araçlarla sunulması, açık devlet verisinin sürekliliği, kişisel gizliliğin ve verilerin paylaşımında fikri mülkiyetin göz önünde bulundurulması, verinin manipüle edilmeye uygun olması, verinin saklanması, servisi ve bakımının maliyeti ve veri kaynakları" süreçleri sırasında yaşanan sorunlar şeklindedir [14]. Martin, Foulonneau, Turki, Ihadjadene ise bir açık veri girişiminde yaşanabilecek riskleri 7 kategoride toplamıştır: yönetişim, ekonomik sorunlar, lisanslar ve yasal mevzular, verinin karakteri, meta veri, erişim ve yetenek [15]. Kucera, Chlapek ise kamu verisinin açılması sürecinde potansiyel riskleri ve bu risklere karşı çözüm önerilerini ilgili riskin seviyesine göre Tablo 1 ve Tablo 2'deki gibi listelemiştir [16].

Tablo 1. Riskler ve Risk Seviyeleri

\begin{tabular}{|c|l|c|}
\hline Risk No & \multicolumn{1}{|c|}{ Risk } & \multicolumn{1}{c|}{$\begin{array}{c}\text { Önem } \\
\text { Seviyesi }\end{array}$} \\
\hline 1 & Mevzuata uygun olmayan verinin paylaşılması & Yüksek \\
\hline 2 & Ticari ilişkilerin gizliliğini ihlal edebilecek veriler & Yüksek \\
\hline 3 & Özel hayatın ihlali & Yüksek \\
\hline 4 & Ülkenin kritik sistemleri hakkında veri & Yüksek \\
\hline 5 & $\begin{array}{l}\text { Paylaşılmasında mevzuat kapsamında bir sıkıntı olmamasına karşın paylaşılması halinde kamu işleyişini } \\
\text { negatif yönde etkileyebilecek veri }\end{array}$ & Orta \\
\hline 6 & Doğru olmayan değerlere sahip veri & Orta \\
\hline 7 & Yanlış yorumlanmaya sebep verebilecek veri & Orta \\
\hline 8 & $\begin{array}{l}\text { Paylaşılması halinde herhangi bir değer üretmeyecek veriler veya herhangi bir kesimin ilgi alanına } \\
\text { girmeyecek veri }\end{array}$ & Orta \\
\hline 9 & Benzer başlık altında farklı değerlere sahip veri paylaşılması & Düşük \\
\hline 10 & $\begin{array}{l}\text { Paylaşılacak veri setinin artışılla birlikte veriyle ilgilenen kesim tarafindan yapılacak geri bildirim } \\
\text { sayısının da artacak olması }\end{array}$ & Düşük \\
\hline
\end{tabular}

\begin{tabular}{|c|c|c|}
\hline \multicolumn{3}{|c|}{ Tablo 1. Çözüm Önerileri } \\
\hline Çözüm No & Çözüm & $\begin{array}{l}\text { İlgili Risk } \\
\text { No }\end{array}$ \\
\hline 1 & $\begin{array}{l}\text { Veri setlerinin paylaşımı konusunda kamu kurumları talepler doğrultusunda değerlendirmeler } \\
\text { yapmalıdır. (Hangi alanda veri setlerinin ilgi gördüğ̈̈, veri setlerinin aldığı oy sonuçları, vb.) }\end{array}$ & R8, R9, R10 \\
\hline 2 & $\begin{array}{l}\text { Hangi kamu kurumunun hangi veri setini yayınlayacağı, ilgili veri setinin başka bir kurum tarafindan } \\
\text { da yayınlanmadığı net bir şekilde belirlenmelidir. }\end{array}$ & $\mathrm{R} 10$ \\
\hline 3 & Paylaşılacak veri setinin herhangi bir mevzuata aykırı olmadığından emin olunmalıdır. & $\mathrm{R} 1, \mathrm{R} 2, \mathrm{R} 3, \mathrm{R} 4$ \\
\hline 4 & $\begin{array}{l}\text { Gizlilikten ötürü paylaşılmasında sorun olabilecek veri setleri anonimleştirilerek paylaşılabilir. Ancak } \\
\text { anonimleştirilerek paylaşılacak veri seti için tersine işlem ile anonimleştirmenin bozulması riski göz } \\
\text { önünde bulundurulmalıdır. }\end{array}$ & R2, R3, R4 \\
\hline 5 & Paylaşılacak verinin doğru veya eksiksiz olduğuna dair kalite kontrolü yapılmalıdır. & $\begin{array}{l}\text { R1, R2, R3, R4, } \\
\text { R5, R6 }\end{array}$ \\
\hline 6 & $\begin{array}{l}\text { Sadece kamu kurumları erişiminde olacağ ve ilgili veri setlerine ait meta verilerinin yer aldığ bir veri } \\
\text { kataloğu oluş̧urulmalıdır. İlgili veri kataloğunda veri setlerinin tabii olduğu mevzuat ve gizlilik } \\
\text { seviyeleri yer alabilir. }\end{array}$ & $\mathrm{R} 1, \mathrm{R} 2, \mathrm{R} 3, \mathrm{R} 4$ \\
\hline 7 & $\begin{array}{l}\text { Herkesin erişebileceği ve ilgili veri setlerine ait meta verilerinin yer aldığı bir veri kataloğu } \\
\text { oluşturulmalıdır. Bu kapsamda; hem kullanıcının veri setlerine ulaşımı kolaylaşacak hem de veri } \\
\text { setlerinin yanlış yorumlanmasının önüne geçilecektir. }\end{array}$ & R7, R8 \\
\hline 8 & Daha önce benzer konularda paylaşılmış veri setlerine erişim bağlantıları paylaşılmalıdır. & R8, R9, R10 \\
\hline 9 & $\begin{array}{l}\text { Vatandaş veya özel sektörden toplanan verilerde eksiklik veya yanlışlık olabileceği gibi ifadeler } \\
\text { belirtilmelidir. }\end{array}$ & R5, R6, R7 \\
\hline 10 & Sonraki dönemde ihtiyaç olabilecek güncellemeler için açık devlet verisi süreçleri takip edilmelidir. & $\mathrm{R} 1, \mathrm{R} 11$ \\
\hline
\end{tabular}




\subsubsection{Ekonomik Boyut}

Kamu verisinin açılması hesap verilebilirliği artıracak, daha kaliteli ve yeni hizmetlere olanak sağlayacak, operasyon maliyetini düşürecek, kamu kurumlarında ve özel sektörde açı inovasyonu teşvik edecektir [17]. Aynı zamanda açı devlet verisinin özel sektör için yeni firsatlar sağlaması beklenmektedir. Avrupa Komisyonu'na göre açık devlet verisinin ekonomik getirisi yıllık 40 milyar avroya ulaşacaktır. McKinsey'nin 2013 yılında açık verinin ekonomik etkisine yönelik yayınladığı raporda ise belirlediği yedi alan dâhilinde açık verinin ABD'de 1.1 trilyon dolar, Avrupa'da 900 milyar dolar, dünyanın geri kalanında ise 800 milyar dolar olmak üzere toplamda yıllık yaklaşık 3 trilyon dolarlık gelir yaratma potansiyeline sahip olduğu ifade edilmiştir [18]. Deloitte'in raporuna göre Birleşik Krallık’ta kardiyak arrestine yönelik verilerin açılmasının ardından ölüm oranlarının azaldığı görülmüşs ve bu da ülke ekonomisine yıllık yaklaşık 400 milyon avroluk katkı sağlamıștır [19]. 2012 yılında Birleşik Krallık'ta girişimci firmalar ve kamuda çalışan doktorların açık olarak paylaşılan reçete verileri üzerinden yaptığı çalışma ile yaklaşık 200 milyon poundluk tasarrufun sağlanabileceği sonucuna ulaşmıştır. Açık devlet verisi ile gerçekleştirilen bu düşük bütçeli 8 haftalık çalışma büyük ölçekte bir tasarrufa ön ayak olmuştur [20].

Kamuda açık veri sürecinin kazandırdığı faydalar oldukça fazladır, ancak böyle bir yapının sürdürebilirliğinin sağlanması beraberinde ekonomik yükümlülükler getirmektedir. Ekonomik boyut; uygulama maliyeti ve açık verinin ülke ekonomisine sağlayacağı katma değer şeklinde ele alınabilir.

Kamuda açık hale getirilmiş, paylaşılmaya hazır verilerin ulusal ya da yerel bir portal üzerinde paylaşılması sürecin en son aşamasıdır fakat böyle bir portal beraberinde donanım, yazılım ve insan kaynağını gerektirir. Bu üç parametre; planlanan uygulamanın büyüklüğüne göre farklı maliyetler oluşturmaktadır. Bazı ülkelere ait açık veri portallarının maliyet tablosu aşağıdaki gibidir [21].

Tablo 2. Açık Devlet Verisi Portal Maliyetleri

\begin{tabular}{|l|l|l|l|l|}
\hline \multicolumn{1}{|c|}{ Platform } & \multicolumn{1}{c|}{ Ülke } & \multicolumn{1}{c|}{ Alan } & \multicolumn{1}{c|}{ Kapsam } & \multicolumn{1}{c|}{ Maliyet } \\
\hline data.gov & ABD & Tüm sektörler & Ulusal & 10 milyon dolar/yll \\
\hline data.gov.uk & Birleşik Krallık & Tüm sektörler & Ulusal & $\begin{array}{l}2010-2011: 1.2 \text { milyon pound } \\
2011-2012: 2 \text { milyon pound }\end{array}$ \\
\hline Etalab & Fransa & Tüm sektörler & Ulusal & 5 milyon Avro/yll \\
\hline $\begin{array}{l}\text { Nantes } \\
\text { Métropole }\end{array}$ & Fransa & Tüm sektörler & Belediye & $\begin{array}{l}100 \text { bin avro (sadece portal } \\
\text { geliştirme maliyeti) }\end{array}$ \\
\hline PortalU & Almanya & Çevre & Ulusal & 750 bin avro/yll \\
\hline
\end{tabular}

17 Eylül 2014 tarihinde Birleşmiş Milletler Kalkınma Programı (UNDP) ile Dünya Bankası, Açık Veri ve Açık Bilgi Kuruluşlarının (The World Bank, The Open Data Institute, Open Knowledge) bir araya gelmesiyle kurulan Açık Veri Ortaklığının (Partnership for Open Data) öncülüğünde 15 ülkeden yetkili kişileri bir araya toplanmıştır. İlgili yetkili kişiler ülkelerindeki açık veri süreçleriyle ilgili iyi örnekleri de paylaşmıştır. Açık veri politikasının uygulanması sürecine ne kadar bir kaynak ayrılmasına yönelik çalışmayı yerine getiren grup maliyetleri Tablo 4 'te görüleceği üzere belli başlıklar altında toplamıştır: 
Tablo 3. Maliyet Türleri

\begin{tabular}{|c|c|}
\hline Maliyet Türü & Alt Başlıklar \\
\hline $\begin{array}{l}\text { 1.Kurulum ve Teknik } \\
\text { Süreçlerin Maliyeti }\end{array}$ & $\begin{array}{l}\text { - Açık veri portalı geliştirme maliyetleri } \\
\text { - } \quad \text { Bulut ve diğer sunucu hizmetlerinin maliyeti } \\
\text { - }\end{array}$ \\
\hline $\begin{array}{l}\text { 2.Planlama ve Yönetim } \\
\text { Maliyeti }\end{array}$ & 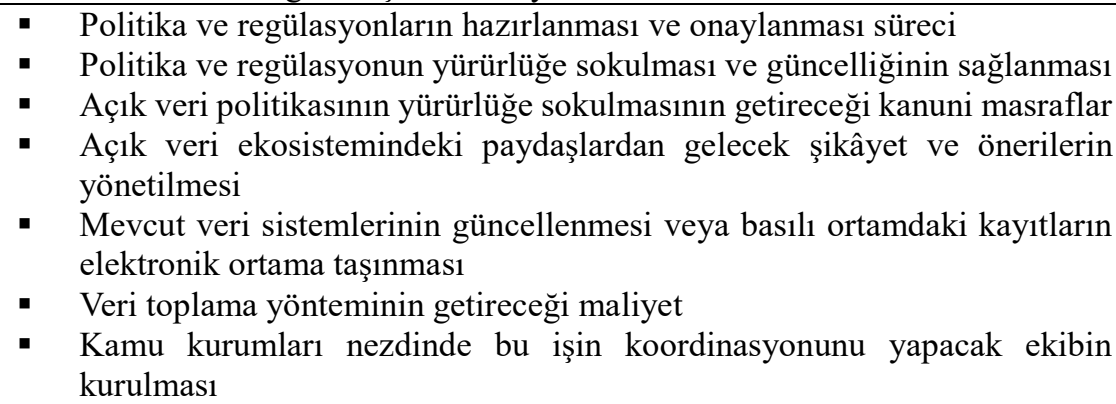 \\
\hline $\begin{array}{l}\text { 3.Beceri Gelişimi ve } \\
\text { Halkla İlişkiler }\end{array}$ & $\begin{array}{ll} & \text { Geliştiricilerin eğitimi } \\
\text { - } & \text { Açı veri kullanımının yaygınlaşmasına yönelik etkinlikler } \\
\text { - } & \text { Halkla iliş̧skileri birimininin koordinasyon maliyeti } \\
\end{array}$ \\
\hline $\begin{array}{l}\text { 4.Sürdürülebilirlik } \\
\text { Maliyeti }\end{array}$ & $\begin{array}{l}\text { - Geliştirilecek sistemin bakım maliyeti } \\
\text { - Peri envanterinin oluşturulması ve yayınlanması } \\
\text { - } \text { Yortalın güncellenmesi ve yönetilmesi } \\
\text { çikabilecek maliyet } \\
\text { Etki analizi maliyeti } \\
\text { - Mevcut ekibin özlük hakları ve eğitim maliyetleri } \\
\text { Portal yazılım bakım maliyeti } \\
\text { Portal yazılım fonksiyonlarının artırılması durumunda ortaya çıkabilecek } \\
\text { maliyetler }\end{array}$ \\
\hline
\end{tabular}

\subsubsection{Standartlar}

Verilerin paylaşılmasında tercih edilen teknolojik altyapı açık veya kapalı olabilmektedir. Bu kapsamda açık format; kullanılan teknolojinin açık kaynak bir yazılım olması, ücretsiz olması, bir kişinin bu teknolojiyi kendi yazılımında tercih etmesinin önünde herhangi bir mülkiyet kanununa tabii olmayacak olmasıdır. Dosya formatının kapalı olması, ilgili teknolojinin fikri mülkiyet haklarının olması ve herkesin erişimine açık olmaması veya belirli yazılımların kısıtlı bir şekilde bu formatları açabilmesidir [22].

Açık veri dosya formatlarının ardından bu veri setlerinin kullanıcıya nasıl sunulacağı da belirlenmelidir. Boyut, karmaşıklık ve sürelilik gibi etkenler verilerin indirilebilir dosya yöntemiyle paylaşılmasını mümkün kılmayabilir. Bazı veri setleri daha küçük modüllere ayrılması gerekirken, bazıları ise güncelliğin sağlanması için canlı akış yöntemiyle sağlanmalıdır. Tablo yapısındaki veriler indirilebilir formatta paylaşılmak için uygunken kısa periyodlarla güncellenen ve tek bir seferde indirilmesinin fazladan maliyete (veri seti boyutu, vb.) sebep yaratabileceği veriler uygulama programlama ara yüzleri (API) tanım bütünüyle sağlanabilir [23]. Veri paylaşacak yetkili kurum, maliyet ve devamlılık faktörlerini dikkate alarak doğru formatı seçmelidir [22].

\subsubsection{Açık Lisans}

Açık verinin yaygınlığının önündeki bariyerlerden biri de lisans sorunudur [24]. Birçok araştırmacıya göre iyi tasarlanmış bir lisans sistemi açık veri girişimini sürdürülebilir ve başarılı kılmak için gereklidir [25]. Open Data Institute'ye göre ise açık verinin kendisinin açık olduğunu belirten bir lisansa sahip olması gerekmektedir, aksi takdirde veri tekrar kullanılamamaktadır [26]. Kamu sektörü verisinin kaynağının toplum olmasında dolayı vatandaş, topluluklar ve şirketlerin açılan veriye yönelik hak ve sorumluluklarının net bir şekilde belirtildiği yasal bir dayanak oluşturmak oldukça önemlidir. Yasal hak ve sorumlulukların net bir şekilde belirtilmemesi açık verinin sağlayacağı ekonomik, sosyal ve devlet yönetimine yönelik katkıların sağlanmasında bir engel olarak yansıyacaktır [27].

Açık lisansa yönelik çalışmalardan bahsedilmeden önce lisans tanımının iyi bir şekilde yapılması önem taşımaktadır. Birleşik Krallık Çerçeve Lisansı'na göre lisans; mevzu bahis bilginin kullanımına müsaade eden yasal belgedir. Aynı zamanda lisans; kişi ve kuruluşlara fikir ve veri haklarıyla korunan belge veya diğer materyalleri tekrar kullanma izni veren yapıdır. İlgili lisansın içeriğginde, kullanıcılara yapabilecekleri işlemler ve kısıtlı koşullar açık bir şekilde belirtilmelidir [28].

Avrupa Komisyonu, Kamu Sektörü Bilgisi (PSI) direktifine uygun olarak yayınladığı rehberde açık lisansın birlik içerisinde ortak bir uygulama olması gerektiğini vurgulanmıştır. Ayrıca bu rehber, ortak kriterler (CC) lisansı gibi açık standart lisanslarının kamu sektörü bilgisinin tekrar kullanımı için yeterli olduğunu, ülke veya birlik özelinde yeni bir standart oluşturulmasının gerekmediği ifade etmektedir [24]. 


\section{PSI Lisansı:}

2003 PSI Direktifi altında PSI lisansı yer almaktadır. Bu lisansa göre kamu sektörü bilgisi ticari ve ticari olmayan amaçlar için kullanılabilmektedir. Ancak ilgili lisansta bazı veri ve bilgiler için belirli ürün ve hizmetlerin ön plana çıkarılmasına yönelik kullanılamayacağına dair kısıtlamalar söz konusudur [29]. Bu kapsamda PSI lisansı açık lisans olarak kabul edilmemektedir.

\section{Ortak Kriterler - CCO:}

CC0 herhangi bir yasal doküman olmayıp, ilgili kuruluşa ait dokümanın haklarından feragat ettiğine dair bir bilgilendirmedir.

\section{Open Data Commons Public Domain Dedication and Licence (PDDL):}

PDDL de CC0'a benzer olarak yasal bir doküman olmayıp fikir ve veri haklarından feragat edildiğine dair bir bilgilendirmedir. Birleşik Krallık [30] ve Kanada [31] gibi ülkeler ise kendi açık veri lisanslarını uyarlamışıtır. Bu lisanslar hem Ortak Kriterler lisansına hem de Açık Veri lisansına uyumludur. Birçok Avrupa Birliği ülkesi de açık veri lisansı olarak Ortak Kriterler lisansını tercih etmiştir.

\subsection{7. Ölçümleme}

2006 yılında Tim Berners-Lee, açık verinin farklı karakteristik özelliklerini ve verinin sunulduğu kitleye hangi faydaları sağlayacağını tanımlamak için 5 yıldız modelini sunmuştur. Bu model verinin tekrar kullanımı sürecinden önce verinin hazırlık seviyesini ölçme konusunda dünyaca kabul görmüş bir modeldir [31]. Birinci yıldızın temel ihtiyaçları göstermesi, beşinci yıldızın ise tüm ihtiyaçları sağlamasıyla 5 yıldız modeli özünde Moslow piramidini temel alır [32]. 5 yıldız modelinde verinin internet ortamında olması, makinece okunabilir olması, açık formatta olması, Kaynak Tanımlama Çerçevesi (RDF) standardına sahip olması ve bağlanabilir olması birer yıldıza karşılık gelir [33]. Berners-Lee'ye göre bir yıldızlı kategoride; veri gözle görülebilir şekilde, taşınabilir doküman formatında internet ortamında yer alır[33]. Korn ve Oppenheim'e göre taşınabilir doküman formatında en çok tercih edilen format PDF'dir. PDF formatında paylaşılan bir dokümana birçok bilgisayardan erişilebilir ancak 1 yıldız kategorisindeki veriler kapalı doküman formatında olmalarından dolayı kullanıcı veriler üzerinde müdahalede bulunamaz [32] ve bu verileri tekrar kullanamaz. Veri internet ortamında olmasının yanında makinece okunabilir formatta (örn. XLS formatında) ise ilgili veri seti 2 yıldızlı kategoride yer alır. Kullanıcı veri setine virgülle ayrılmış değer formatında (CSV) erişebiliyorsa 3 yıldızlı kategoride yer alır. CSV formatı veri işleme ve transfer uygulamaları için oldukça kolaylık sağlayan bir yapıya sahiptir. Ancak çok fazla satır ve sütundan oluşan veri setlerinde karmaşıklığa müsait bir yapıya sahip olmasından dolayı her bir sütun özelinde dokümantasyon yapılması oldukça önemlidir [35]. Veri seti bir evrensel kaynak tanımlayıcısı (URI) yoluyla internet ortamında içeriği paylaşılmışsa 4 yıldız, URI yoluyla başka bir veri setine bağlanmaya uygun formatta paylaşılmışsa 5 yıldız kategorisinde yer alır. Ölçümlemeye yönelik yaklaşımlar Tablo 5 'te gösterilmiştir.

Tablo 5. Ölçümleme Modelleri

\begin{tabular}{|c|c|}
\hline Model Adı & Ölçülecek etken \\
\hline 4 aşama modeli (David Osimo) & $\circ \quad$ Verinin mevcut olmas1 \\
\hline 5 y1ldız modeli (Sir Berners Lee ) & o $\quad$ Verinin mevcut olması \\
\hline $\begin{array}{l}\text { (European Commission Model, } \\
\text { 2011) }\end{array}$ & $\begin{array}{ll} & \text { Mevcuttaki açık veri sayısı } \\
\circ & \text { Güncellik } \\
\circ & \text { Veri formatı } \\
\circ & \text { Verinin yeniden kullanılabilirliği } \\
\circ & \text { Ücret } \\
\circ & \text { Erişilebilirlik } \\
\circ & \text { İndirilebilirdik } \\
\circ & \text { Uygulamalar tarafından anlık erişebilirlik } \\
\circ & \text { Açık veri kullanarak geliştirilen uygulama sayısı }\end{array}$ \\
\hline $\begin{array}{l}\text { Açık veri karşılaştırması (Socrata, } \\
\text { 2011) }\end{array}$ & $\begin{array}{ll} & \text { Verinin mevcut olması } \\
\circ & \text { Erişilebilirlik } \\
\end{array}$ \\
\hline $\begin{array}{l}\text { Puanlama modeli (Open } \\
\text { Knowledge Foundation) }\end{array}$ & $\begin{array}{ll} & \text { Verinin mevcut olması } \\
\circ & \text { Verinin dijital formatı } \\
\circ & \text { Herkesin erişebilmesi } \\
\circ & \text { Ücretsiz olması } \\
\circ & \text { İnternetten erişilebilir olması } \\
\circ & \text { Açı lisansa sahip olması } \\
\circ & \text { Makinece okunabilir olması } \\
\circ & \text { İndirilebilir olması } \\
\circ & \text { Güncel olması } \\
\end{array}$ \\
\hline $\begin{array}{l}\text { Maurino, Spahiu, Batini, Viscusi } \\
\text { [36] }\end{array}$ & $\begin{array}{ll}\circ & \text { Bütünlük } \\
\circ & \text { Doğruluk } \\
\circ & \text { Güncellik } \\
\end{array}$ \\
\hline $\begin{array}{l}\text { Canova, Torchiano Minotas, } \\
\text { Iemma, Morando [37] }\end{array}$ & $\begin{array}{ll} & \text { Takip Edilebilirlik } \\
\circ & \text { Güncellik } \\
\circ & \text { Gecikme } \\
\circ & \text { Bütünlük } \\
\end{array}$ \\
\hline
\end{tabular}




\begin{tabular}{|l|ll|}
\hline & $\circ$ & Uygunluk \\
& $\circ$ & Anlaşlabilirlik \\
& $\circ$ & Doğruluk \\
\hline \multirow{3}{*}{ Ubaldi [3] } & $\circ$ & Veri kalitesi mevcut durum (portal üzerindeki veri seti ve meta veri \\
& & sayıs1) \\
& $\circ$ & Talep (günlük görüntülenme sayısı, vb.) \\
& $\circ$ & Tekrar kullanımı sayısı (veri seti kullanılarak geliştirilen uygulama \\
& sayısı, vb.) \\
\hline
\end{tabular}

\subsubsection{Araçlar}

Tüm kurumun açık verisinin paylaşılması için açık veri portalları ve katalogları bir standart haline gelmeye başlamıştır. Veri setlerinin yüklendiği ve güncellendiği bu portallarda her kesimden son kullanıcı verileri arayabilir ve indirebilecektir. Böyle bir portala yönelik ihtiyaç; kurum içi yazılım geliştirilerek, mevcut bir platform satın alınarak, mevcut bir açık kaynak platform kullanılarak giderilebilir [20].

Open Government Platform (opengovplatform.org), ABD merkezi devlet portalı data.gov'un teknik fonksiyonlarını sunan bir açık kaynak ürünüdür. Açık kaynak olarak sunulan yazılım herhangi bir devlet ya da belediye tarafindan kullanılabilir durumdadır [38].

CKAN (ckan.org), güçlü bir veri yönetim sistemi olup yayınlama, paylaşma, arama araçları ile verinin erişilebilir kılmaktadır. Başta Birleşik Krallık olmak üzere birçok devlet ve yerel organizasyonlar tarafından kullanılmaktadır. CKAN açık kaynak bir yazılım olup herhangi bir kısıtlama olmadan indirilebilir ve kullanılabilir durumdadır. DKAN ise CKAN ile aynı özelliklere sahip olan Drupal altyapısını kullanan bir yazılımdır [38]. Porto Riko Açık Veri Portalı ve Almanya'daki Cologne şehrine ait portal DKAN kullanılarak geliştirilmiştir.

Microsoft OGDI (ogdi.codeplex.com), açık kaynak bir platform olup kurumların kamu verisini paylaşma sürecini etkili ve hızlı bir hale getirmektedir [38].

Socrata, veri paylaşımı, yönetimi, analizi ve tekrar kullanımına olanak sağlayan ticari bir platform olup Chicago, New York ve Bristol şehirleri ile Kenya devletinin açık devlet verisi portalı altyapısını sağlamaktadır [39].

Junar, bulut tabanlı ticari bir açık veri platformu olup veri toplama, zenginleştirme, analizi gerçekleştirme özelliklerine sahiptir. Pasadena, Anaheim ve Santa Clarita şehirlerinin devlet verisi portalı altyapısını sağlamaktadır.

\section{Araştırma Sonuçları ve Tartışma}

\subsection{Kamu Verisini Açarken}

Çalışma kapsamında diğer ülkelerin açık devlet verisi uygulamaları ve politika dokümanları ile uluslararası sivil toplum kuruluşlarının çalışmaları incelenmiş ve edinilen bulgular sonucunda bir model oluşturulmuştur. Oluşturulan bu modelin, hem ulusal düzeyde hem de herhangi bir kamu kurum özelinde mevcut veri ve bilgilerin paylaşılması sürecinde bir rehber olması hedeflenmiştir. İlgili model kapsamındaki bileşenler bu başlık altında paylaşılacaktır.

Kamu tarafında başarılı bir açık devlet verisi sürecinin başlatılabilmesi ve sürdürülebilirliğin sağlanması için iyi bir teknik, yasal ve organizasyonel altyapının oluşturulması oldukça önemlidir [39]. Açık devlet verisine erişimin sağlanabilmesi için birçok devlet açık veri portallarını hizmete sunmuştur. Oluşturulacak ekosistemin merkezinde yer alacak bir portalın başarılı olabilmesi için açık veri stratejisinin başarılı bir şekilde yansıtıldığı bir çerçeve oluşturulması kritiktir.

Önerilen bu modele göre, açık devlet verisi politikasını uygulamaya sokacak bir kamu kurumu için tüm süreç; girişim öncesi dönem, girişimin tasarlanması, girişimin hayata geçirilmesi, girişimin devamlılığı ve uluslararası platformlara katılım olmak üzere 5 kısımdan oluşmaktadır.

\section{Şekil 1. Model Önerisi}

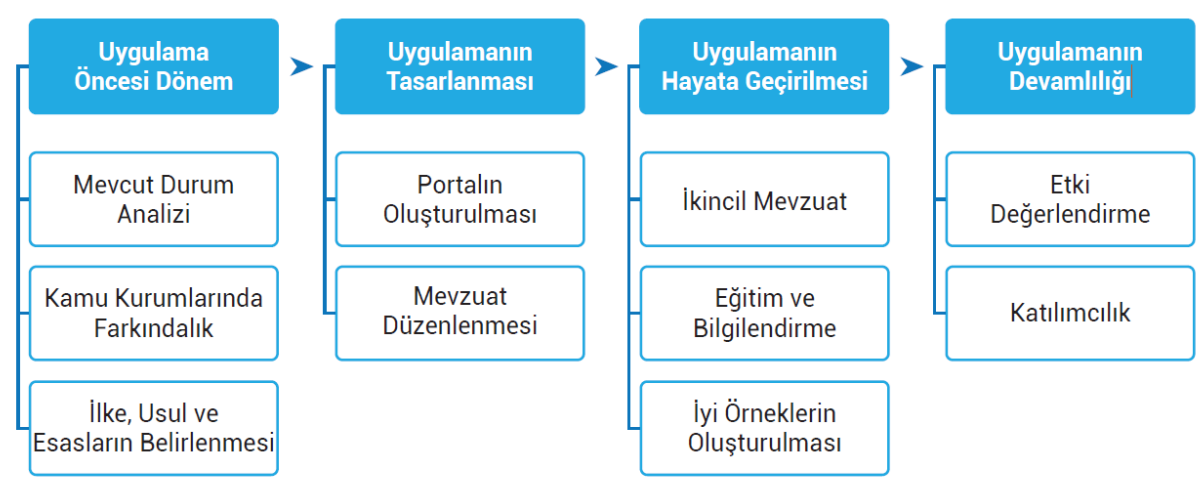




\subsubsection{Uygulama Öncesi Dönem}

Kamu kurumlarında açık devlet verisi uygulamasının gerçekleştirilmesi sürecine yönelik bir aksiyon gerçekleştirilmeden önce mevcut durumun ölçülmesi ve olgunluk seviyesinin belirlenmesi oldukça önemlidir. Bu kapsamda; kamu kurumlarında yer alan veri ve bilgiler meta veri düzeyinde toplanarak veri kataloğu oluşturulmalıdır. Veri katalogları sadece kamu kurumları erişiminde olacağı ve herkesin erişebileceği şeklinde iki farklı türde hazırlanmalıdır. Sadece kamu kurumlarının erişebileceği kataloglar; ilgili veri setlerine ait meta verileri ve veri setlerinin tabii olduğu mevzuat ve gizlilik seviyeleri yer almalıyken, herkesin erişebileceği kataloglarda; ilgili veri setlerine ait meta veriler ve açıklamalar yer almalıdır. Bu sayede; hem kullanıcının veri setlerine ulaşımı kolaylaşacak hem de veri setlerinin yanlış yorumlanmasının önüne geçilecektir.

Farkındalık kapsamında kamu kurumlarının sahip olduğu veri ve bilgilerin tespiti sürecinde kamu kurumları açık devlet verisine yönelik olarak bilgilendirilmesi ilgili kurumların bu süreci sahiplenmesi ve açık devleti uygulamalarını kurum düzeyinde uygulayabilmeleri açısından oldukça önemlidir. Ayrıca daha önce ulusal eylem planında da yer aldığı üzere [40], kurumlarda fizibilite çalışmaları yapılarak hangi verilerin açık veriye dönüştürüleceği belirlenmelidir.

İkinci aşamada mevzuat düzenlemesi kısmında ele alınmadan önce veri paylaşımına ilişkin yasal ve idari engellerin tespiti konusunda bir çalışma yapıllmalıdır.

\subsubsection{Uygulamanin Tasarlanmasi}

Veri paylaşımına ilişkin yasal ve idari engellerin tespiti konusunda gerçekleştirilen çalışma sonucunda bu engellerin giderilmesi için gerekli düzenlemeler hayata geçirilmelidir. Ayrıca açık devlet verisine yönelik uluslararası kriterlere uygun olmak üzere belirlenen ilişkin ilke, usul ve esaslarına göre açık veri paylaşım mevzuatı tanımlanmalıdır. Oluşturulacak mevzuatta telif hakları ve açık lisans konuları, verinin ücretli olması takdirde; verinin toplanıp, saklanıp, paylaşılması sonucu ortaya çıkacak ortalama maliyeti geçmeyecek ücret politikaları, daha önce ulusal eylem planında da yer aldığg üzere [40] kurum verilerinin açık veriye dönüştürülmesi ile ilgili kriterler ve dikkat edilecek hususlar yer almalıdır. Oluşturulacak açık lisans ile verilerin kullanım standartları net bir şekilde ifade edilmelidir.

Açık devlet verisine yönelik uygulama sürecinin tasarlanması ve yasal altyapısının sağlanması adına aksiyonlar atıldıktan sonra ulusal açık veri portalının gerçekleştirilmesine yönelik teknik altyapı çalışmalarına başlanmalıdır.

\subsubsection{Uygulamanın Hayata Geçirilmesi}

Kamu kurumlarının sahip olduğu veri ve bilgileri oluşturulacak portalda uygun formatlarda veya servisler aracılığıyla paylaşması için daha öncesinde hazırlanmış birincil mevzuatlar, ikincil mevzuatlar aracılığıyla desteklenmelidir.

Yayınlanacak ikincil mevzuatları destekleyecek şekilde bir rehber doküman (toolkit) hazırlanmalıdır. Bu doküman; verinin en baştan açık veri standardına uygun bir şekilde toplanması, saklanması ve paylaşılması, hassas içerikli verinin tespiti, gizlilikten ötürü paylaşılmasında sorun olabilecek veri setleri anonimleştirilmesi, anonimleştirilerek paylaşılacak veri seti için tersine işlem ile anonimleştirmenin bozulması riskinin tespiti, portal özelliklerinin kullanım senaryoları unsurlarını içermelidir. Hazırlanacak rehber doküman yanında kamu kurumlarına eğitimler verilmelidir.

Paylaşılacak kamu verisini kullanacak hedef kitle başta olmak üzere tüm vatandaşlar için paylaşılan verilerden anlamlı bilgi elde edilmesi konusunda eğitim dokümanları hazırlanmalı, yerinde ve uzaktan eğitim ortamları hazırlanmalı ve açık devlet verisiyle geliştirilmiş örnek uygulamalar geliştirilmelidir.

\subsubsection{Uygulamanın Devamlılığı}

Açık devlet verisine yönelik uygulama sürecinin devamlılığının sağlanması için belirli periyodlarla açık veri kullanımından dolayı sağlanan katma değerin belirlenmesine yönelik etki değerlendirmesi yapılmalı ve sonrasında alınacak tedbir ve gerçekleştirilecek aksiyonlar bu değerlendirmeler neticesinde uygulanmalıdır.

Ulusal açık veri portalında paylaşılacak veri setlerinin belirlenmesinde veriyi kullanacak paydaşların ihtiyaçları belirlenerek, talep odaklı çalışmaların yürütülmesi sürecin devamlılığı için oldukça önemlidir. Ayrıca açık devlet verisine yönelik uygulama sürecine paydaşların katılımın sağlanmasına yönelik ortamlar oluşturulmalıdır. Örnek olarak; kamu ihtiyaç duyduğu sadece açık devlet verisiyle geliştirilebilir bir uygulamayı kamu iş gücüyle oluşturmak yerine ilana çıkarak ödüllü bir yarışma yoluyla temin edebilir. Bu sayede, kamunun çözüm bulma daveti, mevcut veya yeni fikirlerin bir çözüme veya yeni bir ürüne dönüşmesine sebep olabilecektir. Kamu hem katılımcılığı sağlarken hem de kaynaklarını tasarruf etmiş olacaktır. Bu kapsamda; ulusal açık veri portalında kamu ihtiyaçlarına kullanıcılar tarafından dijital çözümler gerçekleştirilmesine yönelik ödüllü yarışma ilanlarına yer verilmelidir. Açık devlet verisi kullanılarak geliştirilen resmi dijital uygulamalar ise açık kaynak kodlu bir şekilde ulusal açık veri portalında paylaşılmalıdır.

\section{Sonuç}

Dünya genelinde birçok ülkelere ait politika dokümanlarının ve bu ülkelere yönelik gerçekleştirilen akademik çalışmaların incelenmesi neticesinde açık devlet, açık devlet verisi, açık bilgi gibi kavramların ön planda olan kavramlar olduğu görülmüştür. Bu kavramlar e-devlet, tek durak kamu portalı, bilgi toplumu gibi diğer önemli kavramlar ile çoğunlukla ele alınmıştır. Dünya ekonomisinin veri odaklı olmasının da etkisiyle son yıllarda birçok ülke ellerindeki veriden en üst seviyede yararlanabilmek için bu verileri bilgisayarca okunabilir formatta belirli bir kullanım koşuluyla paylaşarak açık devlet verisi süreçlerini uygulamaya sokmuştur. 
Kamunun mevcut verileri ücretsiz bir şekilde sunması inovasyonu ve girişimciliği teşvik edecek, özel sektörde oluşan bu yenilik kamuya ekonomik büyüme ve istihdam olarak geri dönecektir. Kamuda birçok alandaki mevcut problemlere ilişkin çözümler, açık verilerin dijital yöntemler kullanılmasıyla sağlanabilecektir. Doğru analizlerin yapılabilmesi içinse yeterli büyüklükte ve çeşitlilikte veri olmasi gerekmektedir.

Büyük verinin saklanmasına ve analizine yönelik olarak geliştirilen araçlar (Hadoop, Hive, Pig ve NoSQL veritabanları gibi büyük veri teknolojileri) ile yüksek miktardaki veriler üzerinde anlı çözümlemeler yapılabilmektedir. Kamu verisinin açılmasıyla bu teknolojilerle çok hızlı ve katma değeri yüksek verimli projeler üretilebilecektir.

Kamu kurumlarının paylaştığı veriler ile özel sektörden, çeşitli araştırmalar sonucu ortaya çıkan verilerle bağlanması hem ekonomik hem de sosyal birçok firsat sunacaktır. Bu çalışmanın en büyük amacı bu firsatların değerlendirilmesi için hangi aksiyonların gerçekleştirilmesi gerektiğini ortaya koymaktır. Bu çalışma ile birçok kaynakta farklı tanımlarla ifade edilen açık devlet verisine yönelik kapsayıcı bir tanım ortaya koymak, açık devlet verisini yapısal özellik, gelişim ve ihtiyaç sebebi, riskler ve potansiyel engeller, ekonomik boyut, standartlar, açık lisans, ölçümleme, araçlar başlıklarını içeren bir çerçeve üzerinde ele almak ve kamu verisini açmaya yönelik bir model ortaya koymak hedeflenmiştir.

\section{Kaynakça}

[1] Parycek P, Höchtl J, Ginner M. "Open Government Data Implementation Evaluation". Journal Of Theoretical And Applied Electronic Commerce Research, 9(2), 80-99, 2014.

[2] Jetzek, Avital, Andersen. "Generating Value from Open Government Data". 34th International Conference on Information Systems, Milan, 9(2), 1-20, 2013.

[3] Ubaldi B. "Open Government Data: Towards Empirical Analysis of Open Government Data Initiatives”. OECD, 2013.

[4] Deloitte. "Open Data Driving Growth, Ingenuity And Innovation". Deloitte, 2012.

[5] OECD, "Open Government: The Global Context And The Way Forward 2016". OECD, 2016.

[6] Public.Resource.Org. "8 Principles". https://Public.Resource.Org/8_Principles.Html (01.08.2018)

[7] Sunlight Foundation. "Ten Open Data Principles", https://sunlightfoundation.com/policy/documents/ten-open-data-principles (01.08.2018)

[8] Tauberer J. Open Government Data 2nd ed. USA, 2012.

[9] ACM. "Association Of Computing Machinery Recommendation On Open Government". ACM, 2009.

[10]Yu H, Robinson D. G. "The New Ambiguity Of "Open Government". 59 UCLA L. Rev. Disc. 178, 2012.

[11]Vanroekel S., Park T. "Continued Progress And Plans For Open Government Data", https://obamawhitehouse.archives.gov/blog/2014/05/09/continued-progress-and-plans-open-government-data (01.08.2018).

[12]Gurin J. "Open Governments, Open Data: A New Lever For Transparency, Citizen Engagement And Economic Growth". SAIS Review Of International Affairs, 34(1), 71-82, 2014.

[13]Safarov I., Meijer A., Grimmelikhuijsen S. "Utilization Of Open Government Data: Asystematic Literature Review Of Types,Conditions, Effects And Users". Information Polity 22, 1-24, 2017.

[14]Cowan D., Alencar P.,Mcgarry F. "Perspectives On Open Data: Issues And Opportunties". IEEE Technical Report CS-2014-01, 2014.

[15]Martin S., Foulonneau M., Turki S., Ihadjadene M. "Risk Analysis To Overcome Barriers To Open Data" . Université Paris, Vincennes-Saint-Denis, 11(2), 324-388, 2013.

[16]Kucera J., Chlapek D. "Benefits And Risks Of Open Government Data". JOURNAL OF SYSTEMS 34 INTEGRATION 2014/1, 30-41, 2014.

[17]Zeleti T., Ojo A. "Capability Matrix for Open Data". Working Conference on Virtual Enterprises (PROVE), Amsterdam, Netherlands, Oct 2014.

[18]Mckinsey. “Open Data: Unlocking Innovation And Performance With Liquid İnformation”. Mckinsey Global Institute, 2013.

[19]Deloitte. "Market Assessment Of Public Sector İnformation, UK Department For Business Innovation And Skills". Deloitte, 2013.

[20]Scottish Government. “Open Data Resource Pack, Scottish Government”. Scottish Government, 2016.

[21]Martin S., Foulonneau M., Turki S., Ihadjadene M. "Risk Analysis To Overcome Barriers To Open Data". Electronic Journal of eGovernment,11(1), 348-359, 2013.

[22]opendatahandbook.org. "Open Data Handbook". http://opendatahandbook.org/guide/en (01.01.2018)

[23]EU. "European Data Portal", https://www.europeandataportal.eu/elearning/en/module9/\#/id/co-01 (01.01.2018)

[24]Khayyata M., Bannisterb F. “Open Data Licensing: More Than Meets The Eye”. Information Polity 20, 231-252, 2015.

[25]Zuiderwijk A., Susha I., Charalabidis Y., Parycek P., Janssen M. "Open Data Disclosure and Use: Critical Factors From a Case Study". CeDEM15 Conference for E-Democracy and Open Government, Krems, 2015

[26]Bertot J., Jaeger P., Grimes J. M. "Using Icts To Create A Culture Of Transparency: E-Government And Social Media As Openness And Anti-Corruption Tools For Societies". Government Information Quarterly, 27(3), 264-271, 2010.

[27]Korn N., Oppenheim C. "Licensing Open Data: A Practical Guide (Version 2.0)”, Hefce: JISC, Junio, 2011.

[28]National Archives of UK. "UK Government Licensing Framework", http://www.nationalarchives.gov.uk/documents/informationmanagement/uk-government-licensing-framework.pdf (01.01.2018)

[29]“Government Reform Unit Department Of Public Expenditure And Reform, 2015.

[30]National Archives of UK. "Open Government Licence", http://www.nationalarchives.gov.uk/doc/open-governmentlicence/version/3/ (01.01.2018)

[31]Government of Canada, "Open Canada". http://open.canada.ca/en/opengovernment-licence-canada (01.01.2018) 
[32]EPSI. "The Five Stars Of Open Data”, The EPSI Platform, Brussel, 2010.

[33]Berners-Lee T. 5 Star Deployment Scheme For Open Data", https://www.w3.org/designissues/linkeddata.html (01.01.2018)

[34]Korn N, Oppenheim C. "Licensing Open Data: A Practical Guide”. Joint Information Systems Committee (JISC), 2011.

[35]Open Data Handbook. “What Is Open Data?”. http://opendatahandbook.org/en/what-is-open-data/ (01.01.2018)

[36]Maurino A., Spahiu B., Batini C., Viscusi G. "Compliance with Open Government Data Policies: an empirical evaluation of Italian local public administrations”. Information Polity, 19(3), 263-275, 2014.

[37]Canova L., Torchiano M., Minotas C. O., Iemma R., Morando F. "Open data quality measurement framework: Definition and application to Open Government Data”. Government Information Quarterly, 33 (2), 325-337, 2016.

[38]UN. "Guidelines On Open Government Data For Citizen Engagement, Department Of Economic And Social Affairs”. UN, 2013.

[39]Bello O., Akinwande V., Jolayemi O., Ibrahim A. “Open Data Portals in Africa: An Analysis Of Open Government Data Initiatives”. Afr. J. Lib. Arch. \& Inf. Sc., 26(2), 2016.

[40] 2016-2019 Ulusal e-Devlet Stratejisi ve Eylem Plan1, http://www.edevlet.gov.tr/wp-content/uploads/2016/07/2016-2019-Ulusal-eDevlet-Stratejisi-ve-Eylem-Plani.pdf, 2016 